\title{
Impact of Corrective Switching in Wind Farms Operation
}

\author{
Manoel F. de Medeiros Júnior ${ }^{1}$, Arrhenius V. da Costa Oliveira ${ }^{2}$ and Marcus V. Costa de Oliveira $^{2}$ \\ ${ }^{1}$ Department of Computer Engineering and Automation \\ Federal University of Rio Grande do Norte \\ Campus Universitário - Lagoa Nova, Natal (Brazil) \\ Phone/Fax number:+0055 84 32153771, e-mail: firmino@dca.ufrn.br, \\ ${ }^{2}$ Department of Electrical Engineering \\ Federal University of Rio Grande do Norte \\ Campus Universitário - Lagoa Nova, Natal (Brazil) \\ Phone/Fax number:+0055 84 32153731, e-mail: arrhenius@ct.ufrn.br, marcusangra90@ hotmail.com
}

\begin{abstract}
Eventually, limits violations of bus voltages or of admissible loadings of transmission lines and/or power transformers may occur by the power system operation. If violations are detected, corrective measures may be carried out aiming their elimination or to reduce their intensity. Loading shedding is an extreme solution and should only be adopted as the last control action. The control tool adopted in this work is Corrective Switching. It controls power flows in electrical networks by changing their topologies, without requiring any additional cost. Due to the large potential of wind energy in Brazil, using the technique of Corrective Switching may result in disconnection of wind farms, whose machines are not equipped with Low Voltage Ride Through function, since its wind generators are turned off when submitted to voltage sags for a short time. Thus, this works aims to verify if Corrective Switching actions, that could eliminate operational violations in electrical energy systems, can cause disconnections of wind farms, contributing to degrade power quality.
\end{abstract}

\section{Keywords}

Corrective Switching, Electromechanical Transients, Wind Energy.

\section{Introduction}

Power Systems operation is supported by computer simulations and measurement data obtained from monitoring systems. The supervisory process simulates contingencies involving generators, branches or unavailability of substations which could turn the state of an electrical system from a safe state to a situation in which violations of operational limits are present. For eliminating violations, some control measures are usually adopted in order to avoid loading restriction. Within these measures one may emphasize active and reactive power rescheduling, phase shifters adjustment, Corrective Switching, etc. The main advantage of the last control measure compared with the former ones is the economy, once its implementation depends on the operation of existing elements in the system, exclusively.

The technique of Corrective Switching dates from the late 70's, when [1] proposed the disconnection of transmission lines and substation transformers for eliminating overloads. Since then, several algorithms were developed involving Corrective Switching Technique with different applications: eliminate overloads in transmission lines and transformers; solve voltage problems in substation buses; increase power system security. For eliminating violations on power system, the developed algorithms used as corrective measures are: switching on/off of transmission lines and transformers; switching shunt elements; changing-over connections of branches and loads in substations busbars. This last switching measure was developed by [2] in 1980, increasing the search space (the number of switching variants) to be analyzed for obtaining a feasible solution for eliminating overloads in branches. Thus, most developed algorithms over the years consider different approaches to reduce the search space, such as: switching only in substations and transmission lines electrically close to the overloaded branch; discard combinations of variants belonging to different switching nodes; list of more probable effective arrangements for eliminating overloads in a specific branch, assigned offline.

For eliminating overloads in branches, in 1985, a new technique was developed in [3], the Relief Function Methodology, whose main advantage was the low computational effort for testing a switching variant before its realization. In 1987, [4]-[5] improved this methodology including voltage violation. It is noteworthy that the relief functions presented in [3]-[5] were heuristically developed, without considering the reactive power in the system. Later, the relief functions incorporating the reactive power were derived in [6]-[10]. 
The expansion of power supply in Brazil presents a trend to distributed generation. Furthermore, the increasing demand for electricity, guided by good economic times the country is experiencing, brings the need for introducing new energy sources. Based on this fact, wind energy has increased its participation in Brazilian energy matrix, caused by falling generation costs of wind farms, the increasing power of wind turbines and government policies to encourage renewable energy generation.

Due to the increasing demands of maintaining wind farms connected to network, the most modern wind turbines manufactured with Low Voltage Ride Through technology, which allows the wind turbines to keep its operation even in voltage sags situation. However, the first wind turbines installed in Brazil did not have this technical feature.

In case of violations in power systems, alternatives must be sought in order to eliminate or mitigate these violations. Thus, this work will focus on alternatives to eliminate violations by using Corrective Switching technique, changing the connection of branches and loads in a substation. The switching variants able to eliminate violations will be tested on networks with wind turbines without Low Voltage Ride Through technology. Thus, it will be analysed if the employment of Corrective Switching Technique will cause disconnections in wind farms. Analysis of voltage sags will be done by using the software ANATEM - Transient Electromechanical Analysis.

In terms of the structure of this work, the Section I presents an introduction to the technique of switching Correction, aiming to overcome operational violations. Section II presents the Relief Function Methodology. Section III presents the use of wind energy in distributed generation. Finally, Section IV presents objective and main contribution of this work.

\section{Relief Function Methodology}

In order to assist decision of control center operators, it was developed the Relief Function Methodology, which intends to estimate, with few calculations arising from linear approximation, the loading of branches in electrical systems.

For developing a relief function, the concepts of switching nodes and power rerouting presented in [11] will be used. According to [11], switching nodes are the ones where a substantial part of the rerouted overload flows. Figure 1, used in [3]-[5] for obtaining relief functions based on heuristical analysis and considering only active power, illustrates power flow in a representation of a power system equivalent, where it is shown an overloaded branch A-B and a switching node $\mathrm{S}$ with its bus-bars interconnected by a closed circuit breaker. In this figure, $\mathrm{P}_{\text {rat }}$ corresponds to the rated power of the branch, $\Delta \mathrm{P}_{\mathrm{ov}}$ means the branch overload, $\Delta \mathrm{P}_{\text {re }}$ refers to the rerouted power, $\mathrm{P}_{\mathrm{S}}$ is the switching power, $\Delta \mathrm{P}^{\mathrm{s}}$ re refers to the part of $\Delta \mathrm{P}_{\text {re }}$ flowing to node $\mathrm{S}$ and $\Delta \mathrm{P}^{\mathrm{v}}$ re is the part of $\Delta \mathrm{P}_{\text {re }}^{\mathrm{s}}$ flowing through the circuit breaker. Loading on branch A$\mathrm{B}$ is $\mathrm{P}=\mathrm{P}_{\mathrm{rat}}+\Delta \mathrm{P}_{\mathrm{ov}}$. In order to eliminate the overload, it is necessary to reroute power in opposition to $\mathrm{P}$, such as: $\Delta \mathrm{P}_{\mathrm{re}}>\Delta \mathrm{P}_{\mathrm{ov}}$. This procedure is sketched by dotted arrows in Figure 1. It produces power redistribution in all network branches.

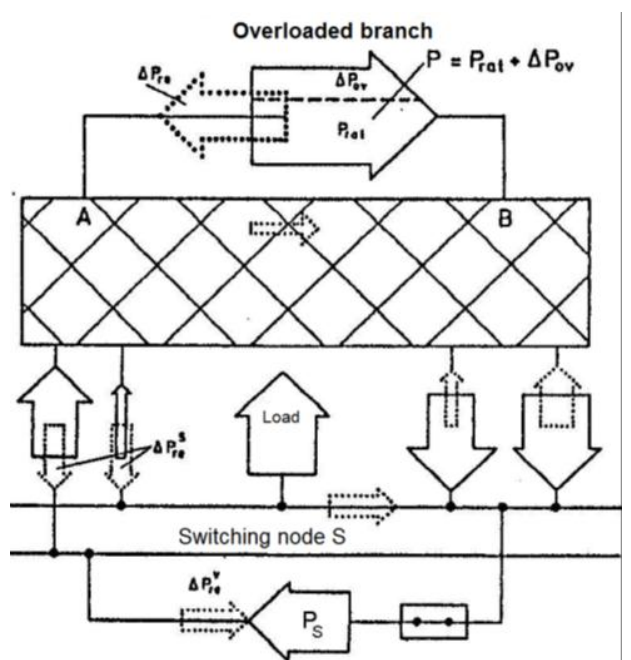

Fig. 1: Representation of a power system equivalent for simulating overload rerouting with bus-bars coupled.

An evolution of [3]-[5] was developed in [6]-[10] which presented relief functions derived analytically, considering reactive power effects. Figure 2 sketches this situation. In this figure, $\mathrm{I}_{\mathrm{AB}}$ is the loading of the overloaded branch in base case; $\mathrm{I}_{\text {nom }}$ corresponds to the rated current of the branch; $I_{\text {sob }}$ means the branch overload; $\mathrm{I}_{\mathrm{re}}$ refers to the rerouted current, $\mathrm{I}_{\text {Switch }}$ is the switching current, $\mathrm{I}_{\text {re }}^{\mathrm{s}}$ refers to the part of $\mathrm{I}_{\mathrm{re}}$ flowing to node $S ; I_{r e}^{v}$ is the part of $\mathrm{I}_{r e}^{\mathrm{S}}$ flowing through the circuit breaker.

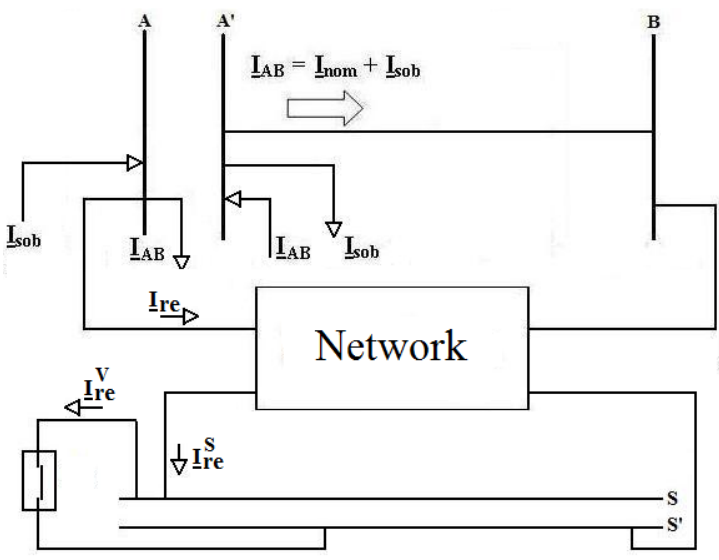

Fig. 2: Representation of a power system equivalent for deriving a relief function.

According to [6]-[10], it is possible to develop a relief functions based on circuit analysis. The equivalent circuit is presented in Figure 3. Considering the circuit showed in this figure, it is necessary to calculate impedances $\underline{Z}_{\text {der }}$, $\underline{Z}_{\text {ser }}, \underline{Z}_{P}$ and $\underline{Z}_{\text {switch }}$, since it is known $\underline{I}_{\text {re }}$ (rerouted current), $\underline{\mathrm{I}}_{\mathrm{re}} \mathrm{S}$ (part of $\underline{\mathrm{I}}_{\mathrm{re}}$ flowing to switching node $\mathrm{S}$ ), $\underline{\mathrm{I}}_{\mathrm{re}}^{\mathrm{V}}$ (part of $\underline{\mathrm{I}}_{\mathrm{re}} \mathrm{S}$ flowing through the circuit breaker that links bus-bar $\mathrm{S}$ and $\left.\mathrm{S}^{\prime}\right), \underline{\mathrm{Z}}_{\mathrm{AB}}$ (impedance on overloaded branch), $\underline{\mathrm{V}}^{\mathrm{re}}{ }_{\mathrm{AA}}$ ' (voltage difference between nodes $A$ and $A^{\prime}$ for overload rerouting case) e $\underline{\mathrm{V}}^{\mathrm{re}}{ }^{\prime} \mathrm{B}$ (voltage difference between nodes A' and B for overload rerouting case). 


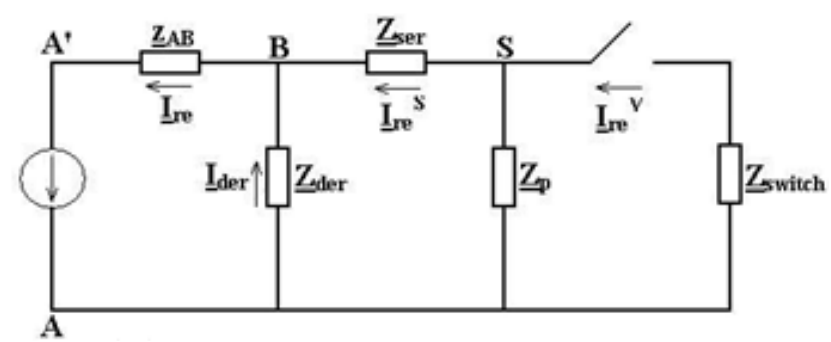

Fig. 3: Representation of overload rerouting using circuit analysis.

According to [6]-[10], circuit impedances in Figure 3 are obtained using (1), (2), (3), (4) and (5).

$$
\begin{gathered}
\underline{\mathrm{I}}_{\mathrm{re}}^{\mathrm{S}}=\mathrm{k} \cdot \underline{\mathrm{I}}_{\mathrm{re}} \\
\underline{\mathrm{Z}}_{\mathrm{der}}=-\frac{\underline{\mathrm{V}}_{\mathrm{A}^{\prime} \mathrm{A}}^{\mathrm{re}}+\underline{\mathrm{Z}}_{\mathrm{AB}} \cdot \underline{\mathrm{I}}_{\mathrm{re}}}{\underline{\mathrm{I}}_{\mathrm{re}} \cdot(1-\mathrm{k})} \\
\underline{\mathrm{Z}}_{\mathrm{ser}}=\frac{\underline{\mathrm{V}}_{\mathrm{SA}}^{\mathrm{re}}-\underline{\mathrm{V}}_{\mathrm{BA}}^{\mathrm{re}}}{\mathrm{k} \cdot \underline{\mathrm{I}}_{\mathrm{re}}} \\
\underline{\mathrm{Z}}_{\mathrm{switch}}=\frac{-\left(\frac{\underline{\mathrm{V}}_{\mathrm{BA}}^{\mathrm{re}}+\underline{\mathrm{Z}}_{\mathrm{ser}}}{\underline{\mathrm{I}}_{\mathrm{re}}^{\mathrm{S}}}\right)}{\underline{\mathrm{I}}_{\mathrm{re}}^{\mathrm{V}} / \underline{\mathrm{I}}_{\mathrm{re}}^{\mathrm{S}}} \\
\underline{\mathrm{Z}}_{\mathrm{P}}=\frac{-\left(\frac{\underline{\mathrm{V}}_{\mathrm{BA}}^{\mathrm{re}}+\underline{\mathrm{Z}}_{\mathrm{ser}}}{\underline{\underline{I}}_{\mathrm{re}}^{\mathrm{S}}}\right)}{1-\left(\underline{\mathrm{I}}_{\mathrm{re}}^{\mathrm{V}} / \underline{\mathrm{I}}_{\mathrm{re}}^{\mathrm{S}}\right)}
\end{gathered}
$$

Since impedances of circuit in Figure 3 are known, current variation $\Delta \underline{I}$ on branch $\mathrm{A}-\mathrm{B}$ after switching variant realization is calculated using circuit presented in Figure 4.

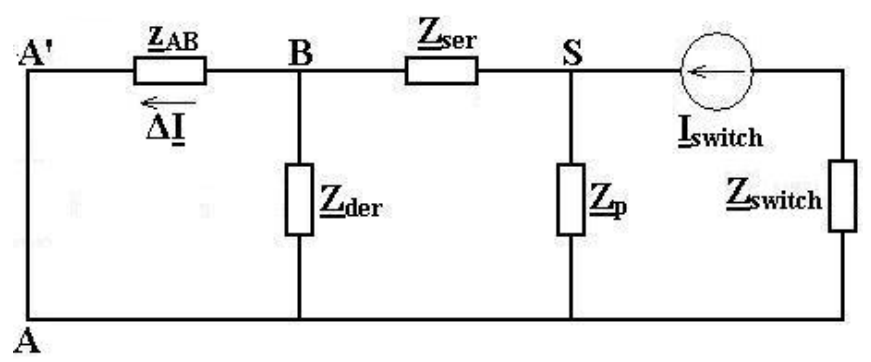

Fig. 4: Representation of current estimate on branch A-B after switching variant realization.

In this circuit, $\underline{I}_{\text {switch }}$ is current flowing through the circuit breaker that links bus-bars on switching node S. This current is obtained from load flow calculation on base case. Current variation on branch A-B after switching variant realizations is calculated by (6), where impedance $\underline{Z}_{1}$ is calculated using (7). In (8), it is calculated $\underline{I}_{A B}{ }^{A B T S N}$, current on branch after splitting buses $\mathrm{S}$ and $\mathrm{S}$ '.

$$
\begin{gathered}
\Delta \underline{I}=\frac{\underline{Z}_{\text {der }}}{\underline{Z}_{\text {der }}+\underline{Z}_{\mathrm{AB}}} \cdot \frac{\underline{Z}_{\mathrm{P}}}{\underline{Z}_{\mathrm{P}}+\underline{Z}_{1}} \cdot \underline{\mathrm{I}}_{\text {switch }} \\
\underline{\mathrm{Z}}_{1}=\underline{\mathrm{Z}}_{\mathrm{ser}}+\frac{\underline{\mathrm{Z}}_{\mathrm{der}} \cdot \underline{\mathrm{Z}}_{\mathrm{AB}}}{\underline{\mathrm{Z}}_{\mathrm{der}}+\underline{\mathrm{Z}}_{\mathrm{AB}}} \\
\mathrm{I}_{\mathrm{AB}}^{\mathrm{ABTSN}}=\mathrm{I}_{\mathrm{AB}}^{\mathrm{cb}}+\Delta \underline{\mathrm{I}}
\end{gathered}
$$

Since relief function is developed, the loading of branches, after realization of any switching variants, is quickly estimated by simple calculations. Thus, those variants which, after its realization, result in overloaded branches are discarded. The remaining variants are nominated as relief variants.

These variants are an essential part of this work. It will be analyzed the impact of relief variants realization in the operation of wind farms without Low Voltage Ride Through function.

\section{Wind Turbines Interconnected to an Electrical Distribution Network}

Actually, electricity generation from wind farms is emerging as one of the most used forms of distributed generation used in the world. For using this form of energy in large, it is necessary to develop models to study the impacts of the introduction of this new mode of electricity generation in electrical systems.

Studies show that wind turbines connected directly to the power grid have some susceptibility to events that may occur in the electrical system. Voltage sags caused by short-circuit near a wind farm may be able to cause its disconnection, since the voltage variation is around $10 \%$ of rated voltage and with duration greater than $150 \mathrm{~ms}$.

Due to the increasing demands of maintaining wind farms connected to network, the most modern wind turbines manufactured with Low Voltage Ride Through technology, which allows the wind turbines to keep its operation even in voltage sags over $10 \%$ of rated voltage and with duration greater than $150 \mathrm{~ms}$.

Thus, the employment of the technique of Corrective Switching in networks with wind generation interconnected must be preceded by studies which provide the impacts caused by switching actions, since these produce voltage variations.

Figure 5 illustrates a real network, rated voltage $69 \mathrm{kV}$, with 22 bars and a wind farm producing $32.0 \mathrm{MW}$ interconnected to bar 11 . Initially, consider the network operating without contingencies and the wind farm dispatching all generated power. Bars 22 and 12 belong to same substation with double bus-bars.

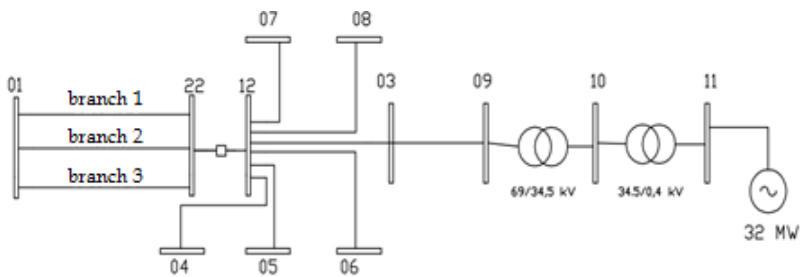

Fig. 5: Real network with a wind farm interconnected to bar 11.

Consider a short-circuit on branch 2 that links bar 1 to bar 2. Due to this fault, branch 2 and wind farm will be disconnected, resulting in $14.3 \%$ of overload on branch 3 . Table I presents the results. 
Table I. - Loading of branches before and after contingency on branch 2

\begin{tabular}{|c|c|c|}
\hline & $\begin{array}{c}\text { Loading of branches } \\
\text { before contingency }(\%)\end{array}$ & $\begin{array}{c}\text { Loading of branches } \\
\text { after contingency }(\%)\end{array}$ \\
\hline Branch 1 & 36.60 & 51.20 \\
\hline Branch 2 & 33.60 & - \\
\hline Branch 3 & 63.40 & 114.30 \\
\hline
\end{tabular}

Using Corrective Switching technique, the interconnection of branches and load on bus bars 12 and 22 is changed, producing new loadings on braches 1 and 3 . Figure 6 presents a switching variant for bus bars 12 and 22 .

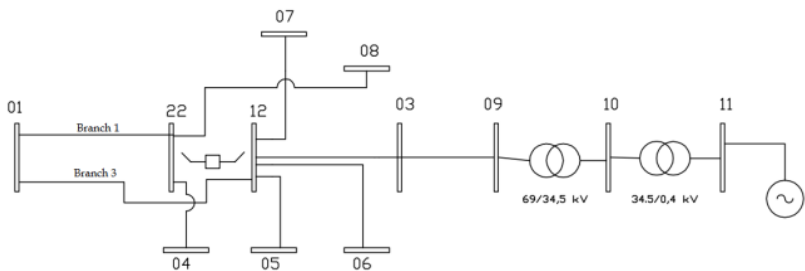

Fig. 6: Example of switching variant for bus bars 12 and 22 for changing the loading of branches 1 and 3 .

Using any switching variant is not guaranteed that the loading of branch 3 will be relieved. Thus, it will be employed the Relief Function methodology, presented in Section II, for selecting variants that result in overload elimination for branch 3 . These variants will be nominated as relief variants.

\section{Simulation and Results}

The methodology presented on Section II was simulated using a computer with $1.8 \mathrm{GHz}$ processor and 1GB RAMmemory, and software Scilab (version 4.1.2). For bus bars 12 and $22,2^{8}$ switching variants are available. Using Relief Function Methodology, the loadings of branch 3 after the realization of all $2^{8}$ switching variants were estimated. These estimates were processed in less than 0.5 seconds. Analysing all $2^{8}$ switching variants, just 5 variants have proved to be success promising for eliminating overload on branch 3 . However, considering the wind turbines connected to bar 11 do not have Low Voltage Ride Through technology, it is necessary verify if the realization of any of these 5 relief variants causes disconnection to the wind farm. The results for these relief variants are presented below.

\section{A. Variant 1}

Figure 7 illustrates the switching variant involving bus bars 12 and 22 for relieving overload on branch 3. Table II presents the loading for branches 1 and 3.

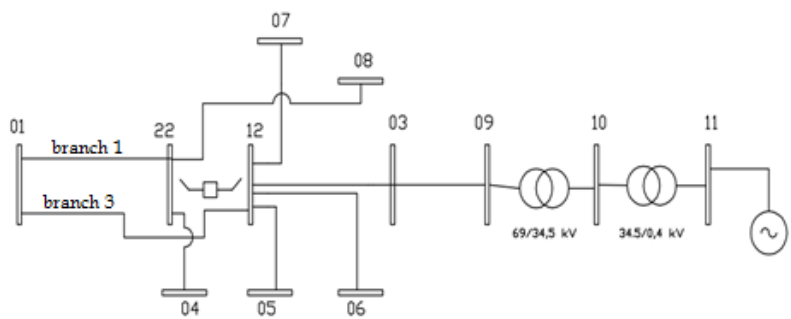

Fig. 7: Variant 1 used for eliminate overload on branch 3.
Table II. - Loading of branches after contingency on branch 2 and after realization of variant 2

\begin{tabular}{|c|c|c|}
\hline & $\begin{array}{c}\text { Loading of } \\
\text { branches after } \\
\text { contingency }(\%)\end{array}$ & $\begin{array}{c}\text { Loading of branches } \\
\text { after realization of } \\
\text { variant 1 }(\%)\end{array}$ \\
\hline Branch 1 & 51.20 & 67.10 \\
\hline Branch 2 & - & - \\
\hline Branch 3 & 114.30 & 99.70 \\
\hline
\end{tabular}

Figure 8 shows voltage profile on bar 11 before and after the realization of variant 1 . Even without Low Voltage Ride Through Technology, the wind farm keeps connected to network. Figure 9 presents active power produced by the wind farm. This way, the realization of variant 1 does not disconnect wind farm to the network.

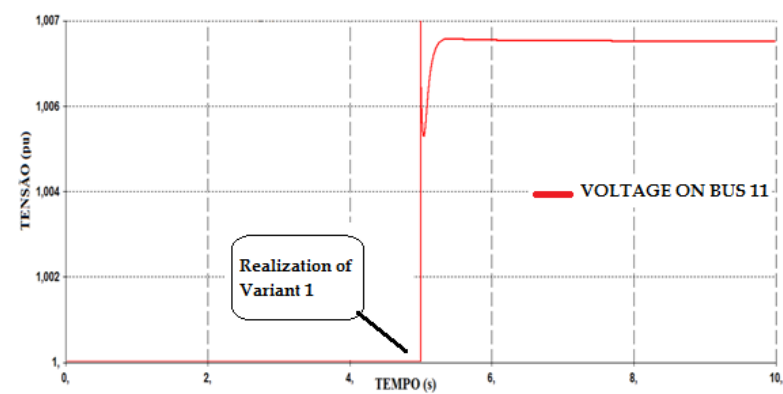

Fig. 8: Voltage profile on bar 11 before and after the realization of variant 1 .

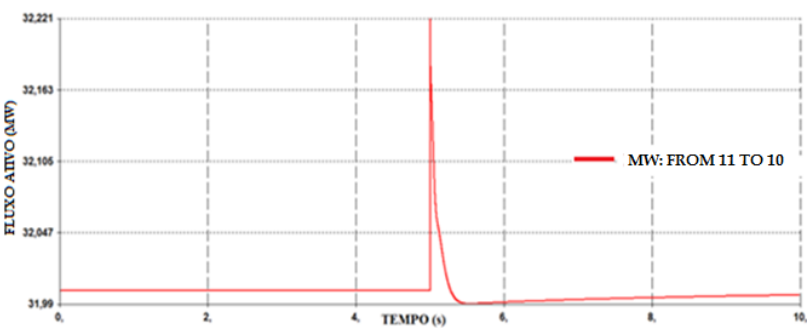

Fig. 9: Active power produced by the wind farm before and after the realization of variant 1 .

\section{B. Variant 2}

Figure 10 illustrates the switching variant involving bus bars 12 and 22 for relieving overload on branch 3 . Table III presents the loading for branches 1 and 3 .

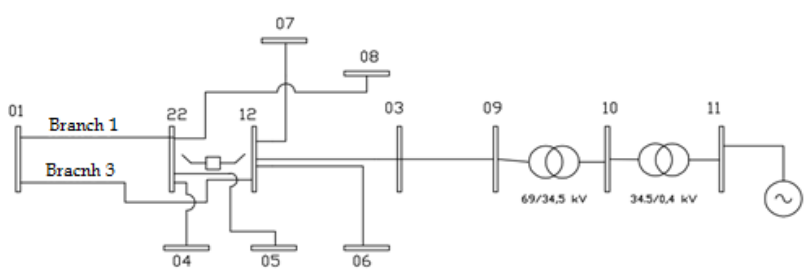

Fig. 10: Variant 2 used for eliminate overload on branch 3.

Table III. - Loading of branches after outage of branch 2 and after realization of variant 2

\begin{tabular}{|c|c|c|}
\hline & $\begin{array}{c}\text { Loading of } \\
\text { branches after } \\
\text { contingency }(\%)\end{array}$ & $\begin{array}{c}\text { Loading of branches } \\
\text { after realization of } \\
\text { variant 2 }(\%)\end{array}$ \\
\hline Branch 1 & 51.20 & 87.20 \\
\hline Branch 2 & - & - \\
\hline Branch 3 & 114.30 & 84.50 \\
\hline
\end{tabular}


Figure 11 shows voltage profile on bar 11 before and after the realization of variant 2. Even without Low Voltage Ride Through Technology, the wind farm keeps connected to network. Figure 12 presents active power produced by the wind farm. This way, the realization of variant 2 does not disconnect wind farm to the network.

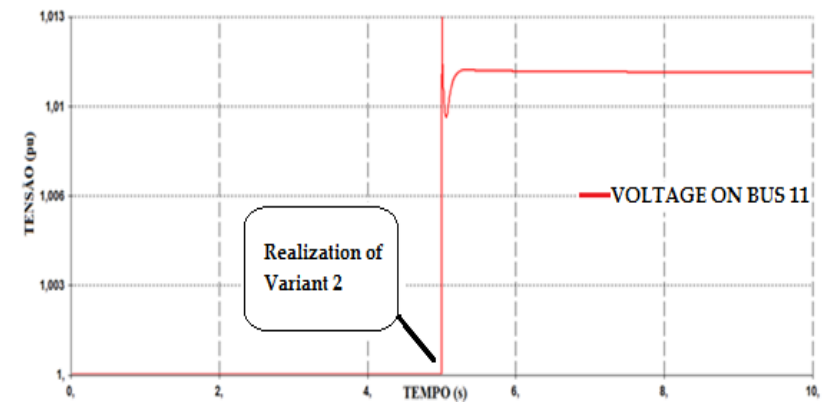

Fig. 11: Voltage profile on bar 11before and after the realization of variant 2 .

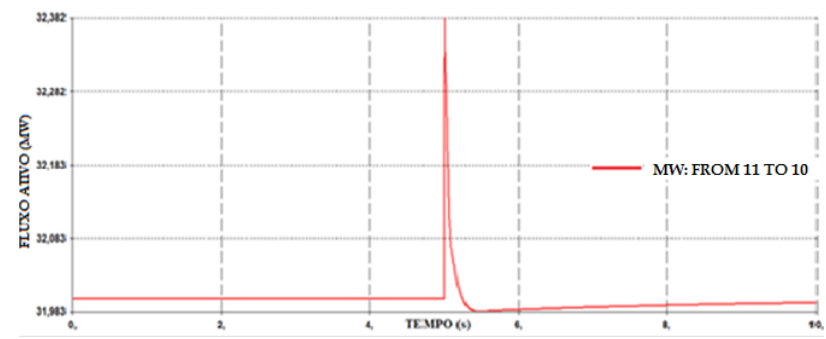

Fig. 12: Active power produced by the wind farm before and after the realization of variant 2 .

\section{Variant 3}

Figure 13 illustrates the switching variant involving bus bars 12 and 22 for relieving overload on branch 3. Table IV presents the loading for branches 1 and 3 .

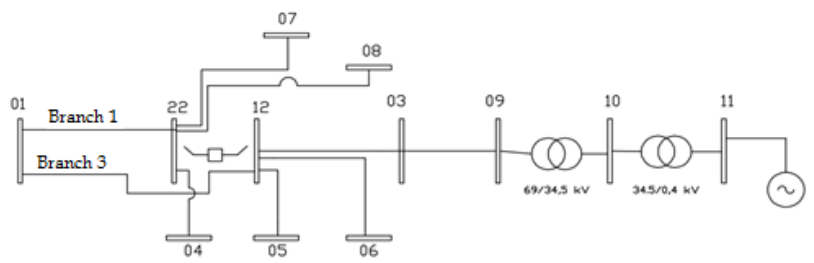

Fig. 13: Variant 3 used for eliminate overload on branch 3.

Table IV. - Loading of branches after contingency on branch 2 and after realization of variant 3

\begin{tabular}{|c|c|c|}
\hline & $\begin{array}{c}\text { Loading of } \\
\text { branches after } \\
\text { contingency }(\%)\end{array}$ & $\begin{array}{c}\text { Loading of branches } \\
\text { after realization of } \\
\text { variant 3 }(\%)\end{array}$ \\
\hline Branch 1 & 51.20 & 90.40 \\
\hline Branch 2 & - & - \\
\hline Branch 3 & 114.30 & 84.60 \\
\hline
\end{tabular}

Figure 14 shows voltage profile on bar 11 before and after the realization of variant 3 . Even without Low Voltage Ride Through Technology, the wind farm keeps connected to network. Figure 15 presents active power produced by the wind farm. This way, the realization of variant 3 does not disconnect wind farm to the network.

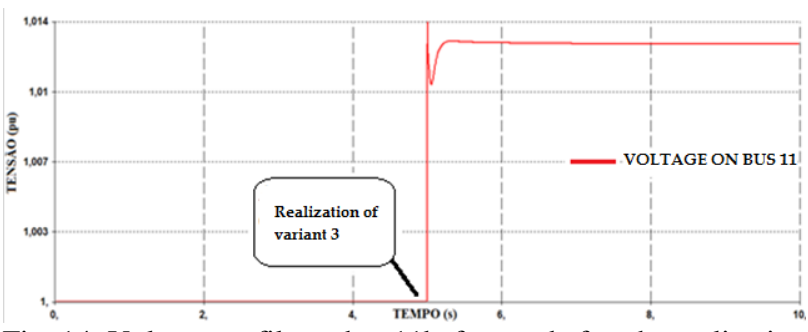

Fig. 14: Voltage profile on bar 11 before and after the realization of variant 3 .

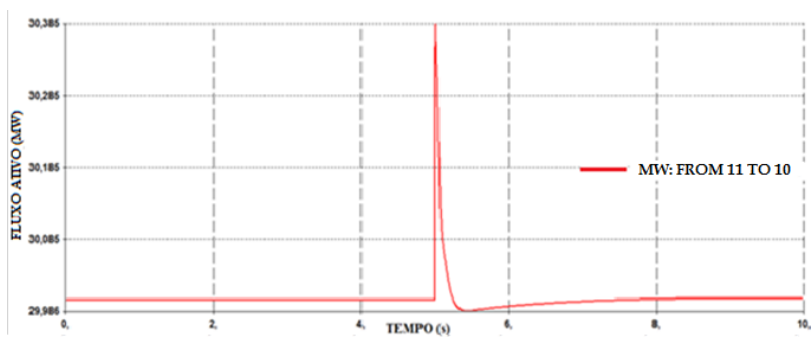

Fig. 15: Active power produced by the wind farm before and after the realization of variant 3 .

\section{Variant 4}

Figure 16 illustrates the switching variant involving bus bars 12 and 22 for relieving overload on branch 3. Table $\mathrm{V}$ presents the loading for branches 1 and 3 .

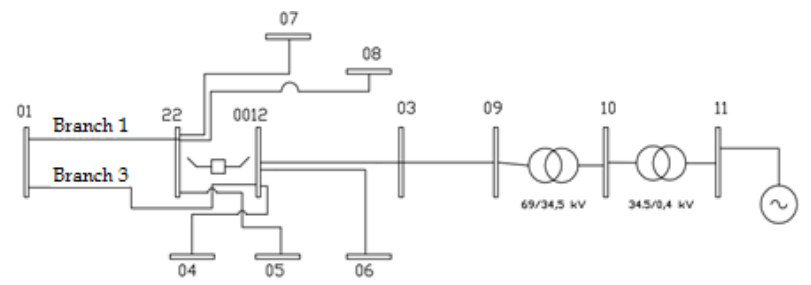

Fig. 16: Variant 4 used for eliminate overload on branch 3.

Table V. - Loading of branches after contingency on branch 2 and after realization of variant 4

\begin{tabular}{|c|c|c|}
\hline & $\begin{array}{c}\text { Loading of } \\
\text { branches after } \\
\text { contingency }(\%)\end{array}$ & $\begin{array}{c}\text { Loading of branches } \\
\text { after realization of } \\
\text { variant 4 }(\%)\end{array}$ \\
\hline Branch 1 & 51.20 & 69.40 \\
\hline Branch 2 & - & - \\
\hline Branch 3 & 114.30 & 98.80 \\
\hline
\end{tabular}

Figure 17 shows voltage profile on bar 11 before and after the realization of variant 4. Even without Low Voltage Ride Through Technology, the wind farm keeps connected to network. Figure 18 presents active power produced by the wind farm. This way, the realization of variant 3 does not disconnect wind farm to the network.

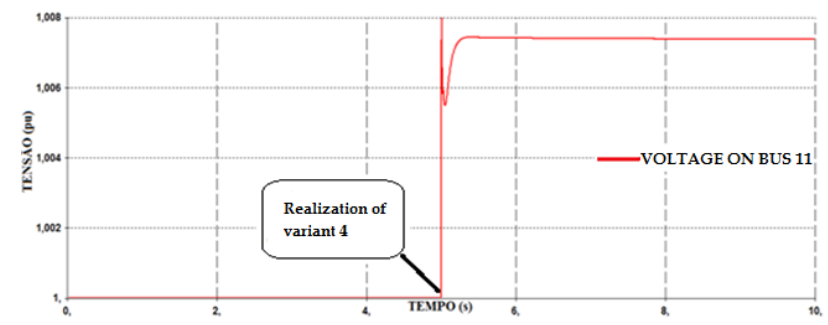

Fig. 17: Voltage profile on bar 11 before and after the realization of variant 4 . 


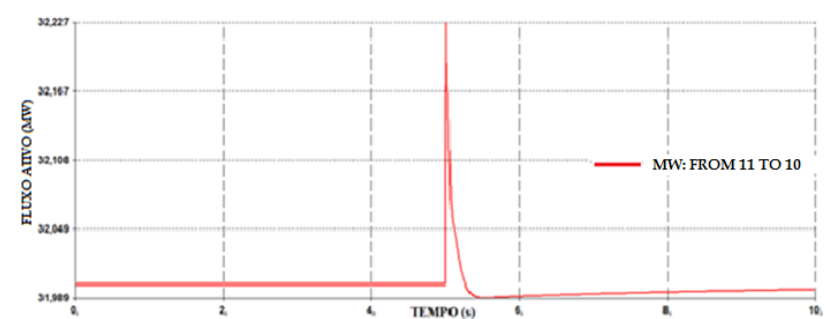

Fig. 18: Active power produced by the wind farm before and after the realization of variant 4

\section{E. Variant 5}

Figure 19 illustrates the switching variant involving bus bars 12 and 22 for relieving overload on branch 3 . Table VI presents the loading for branches 1 and 3.

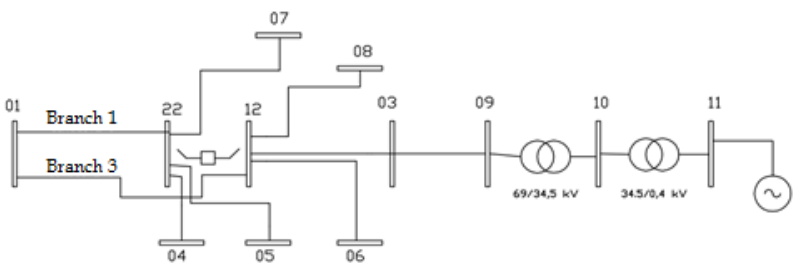

Fig. 19: Variant 5 used for eliminate overload on branch 3.

Table VI. - Loading of branches after contingency on branch 2 and after realization of variant 5

\begin{tabular}{|c|c|c|}
\hline & $\begin{array}{c}\text { Loading of } \\
\text { branches after } \\
\text { contingency }(\%)\end{array}$ & $\begin{array}{c}\text { Loading of branches } \\
\text { after realization of } \\
\text { variant 5 }(\%)\end{array}$ \\
\hline Branch 1 & 51.20 & 79.70 \\
\hline Branch 2 & - & - \\
\hline Branch 3 & 114.30 & 90.90 \\
\hline
\end{tabular}

Figure 20 shows voltage profile on bar 11 before and after the realization of variant 5. Even without Low Voltage Ride Through Technology, the wind farm keeps connected to network. Figure 21 presents active power produced by the wind farm. This way, the realization of variant 3 does not disconnect wind farm to the network.

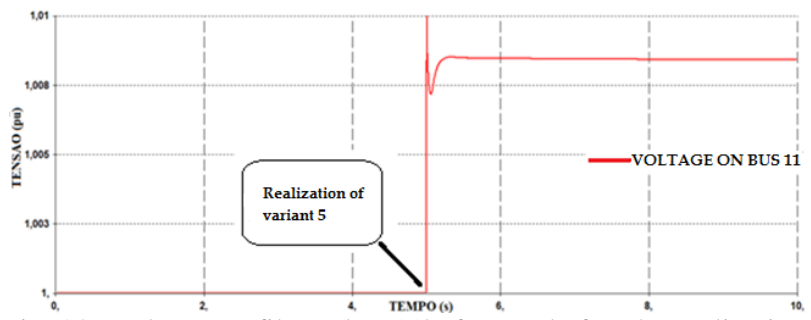

Fig. 20: Voltage profile on bar 11before and after the realization of variant 5 .

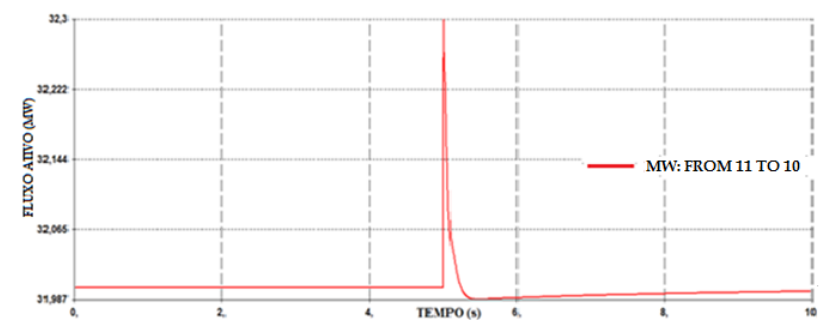

Fig. 21: Active power produced by the wind farm before and after the realization of variant 5 .

\section{Conclusions}

The proposed methodology allowed the determination of feasible variants for eliminating overloads on branches with very small computational effort. This was possible just because of using the Relief Function. The evaluation of $2^{8}$ possible variants could be carried out in less than 0.5 seconds.

The simulations accomplished with the adopted test system have shown that, even for wind turbines without Low Voltage Ride Through technology, the practical realization of any relief variants presented in this paper will not disconnect the wind farm from the network.

For future works, it is important to analyse the impact of switching measures in networks with several wind farms, also considering wind turbines without Low Voltage Ride Through technology, and their dynamical behaviour.

\section{References}

[1] H. Müller, "Zustandskorrektur von gefährdeten Netzen durch Abschalten von Betriebsmitteln," etz-Archiv, vol. 1, pp. 95-97, 1979.

[2] H. -J. Koglin, and H. Müller, "Overload reduction through corrective switching actions," in Proc. 1980 IEE International Conference on Power System Monitoring and Control, pp. 159-164.

[3] H. -J. Koglin and M. F. Medeiros Júnior, "Corrective Switching Approaching on-line Application," in Proc. 1985 CIGRE/IFAC Symposium on Planning and Operation of Electric Energy Systems, pp. 237-241.

[4] H. -J. Koglin and M. F. Medeiros Júnior, "Corrective Switching by Means of Optimal Strategy," in Proc. 1987 Power System Computation Conference, pp. 804-809.

[5] M. F. Medeiros Júnior, "Schnelle Überlastreduktion Durch Korrektives Schalten," Ph.D. dissertation, TH Darmstadt, Alemanha, 1987.

[6] M. F. Medeiros Júnior e A. V. C. Oliveira, "Dedução e Testes de Funções de Alívio para Estimar a Influência de Medidas de Chaveamento na Eliminação de Sobrecargas," in Proc. Industry Conference Application, CD-ROM, 2010.

[7] M. F. Medeiros Júnior, J. T. Oliveira e A. V. C. Oliveira, "Desenvolvimento e Testes de um Modelo Linear para Estimar o Carregamento de Ramos de um Sistema Elétrico após Adoção de Medidas de Chaveamento," in Proc. 2010 T\&D Latin America, CD-ROM, 2010.

[8] A. V. C. Oliveira, "Dedução de Funções de Alívio para Priorização de Variantes de Chaveamento Adequadas à Eliminação de Sobrecargas," Tese de Doutorado, Universidade Federal do Rio Grande do Norte, Brasil, 2011.

[9] M. F. Medeiros Júnior, J. T. Oliveira, A. V. C. Oliveira and J. O. Medeiros, "Deriving Analytical Relief Functions for Switching Variants and Assigning Priority by Transient Analysis," in Proc. Power System Computation Conference, 2011, PEN-DRIVE.

[10] M. F. Medeiros Júnior, e A. V. C. Oliveira, "Dedução de Funções de Alívio para Estimar a Influência de Medidas de Chaveamento na Eliminação de Sobrecargas a Partir da Técnica de Injeção Reversa," Sba Controle \& Automação, Vol. 23, No 4, pp. 489-507.

[11] H. Müller, " Korrektives Schalten - Eine Mabnahme zur gezielten Entlastung von Betriebsmitteln in elektrischen Energieversorgungsnetzen," Ph.D. dissertation, TH Darmstadt, Alemanha, 1981. 